\title{
Applying interprofessional education to the practice setting
}

\section{Authors: Susan Way and Leigh-Ann Dixon}

The aim of this paper is to explore how interprofessional education (IPE) has been incorporated into a group of final year undergraduate healthcare curricula. After highlighting the importance of IPE an illustration of how it is applied to practice will be given using the example of a service improvement project where students developed a video to improve community staff's ability to access learning material in relation to recognising, assessing and acting on community-acquired infection. The opportunities and learning achieved within the module are discussed alongside some of the challenges.

Interprofessional education can be defined as occurring when people from two or more professions, including students, learn with, from, and about each other (Centre for the Advancement of Interprofessional Education 2018). Interprofessional education has been delivered in higher education for a number of years, particularly in healthcare undergraduate curricula such as nursing, midwifery and professions allied to health (Nursing and Midwifery Council 2009 and 2018 , Health and Care Professions Council 2017). Effective IPE and collaboration amongst interprofessional groups is suggested by the World Health Organisation (WHO 2010) to improve quality care for individuals, families and communities. However, recent high profile investigatory reports into adverse incidents in the UK National Health Service (NHS) questions the translation of IPE from the classroom into practice (Francis 2013; Kirkup 2015). It is therefore important to embed practical application of IPE in undergraduate healthcare education in order to ensure that the future, newly qualified workforce embraces collaborative working as part of their daily practice.

\section{Applying IPE to the practice setting}

Acknowledging the failings identified by Francis (2013) and Kirkup (2015), a university in the south of England looked to address how it implemented IPE to facilitate final year undergraduate healthcare students to work effectively as part of a multiprofessional team. Service improvement projects were used to provide the means to translate learning about IPE from the classroom and apply it to practice. Service improvement most often refers to change in services that aim to improve the experience of people who use them (Gage 2013).

Students at the university are expected to work in small groups and collaborate with practice partners in the NHS, private or voluntary sector, referred to as stakeholders, to identify an area that needs improvement. The aim of working in small interprofessional groups is to help prepare students for complex team working that they will encounter as part of their professional career 
(Gagnon and Roberge 2012) and the service improvement project was the means to facilitate this. The benefits include students getting to work on a project in clinical practice with the potential for real impact and therefore have contemporary relevance to the well-being of individuals and/or communities. The stakeholder gets the opportunity to benefit from the students' knowledge, skills and creativity while gaining valuable insights into their specific project area.

\section{The service improvement project module}

The projects are undertaken by approximately six students per group from professional backgrounds which include midwifery, adult nursing, mental health nursing, children and young people's nursing physiotherapy and occupational therapy. Students are assigned to the groups mainly for practical reasons as numbers are often in excess of 420 . This also ensures a mix of professions per group, although adult nurses often are the dominate profession by virtue of their large cohort size. The 20 credit, undergraduate, final year module runs twice a year over approximately five months and culminates in students being assessed via an individually completed reflective account and a group presentation. They are required to present and defend the outcome of their project, referred to as the product, to an invited audience.

At the start of the module the students have an introductory morning explaining the purpose of the module and its self-directed, interprofessional style of learning. The students then get together in their allocated groups and spend time getting to know each other by completing a number of guided activities, which includes their strengths and weaknesses in relation to the requirements of the module. Following the introductory session the students in their IPE groups are offered three further facilitated sessions of two hours each.

\section{The service improvement project}

Sepsis is a life-threatening condition affecting an estimated 150,000 people per year (UK Sepsis Trust 2017) with up to $80 \%$ of infections being acquired in the community (National Confidential Enquiry into Patient Outcome Death 2015). Evidence identifies that the use of prehospital (community) sepsis screening tools improve outcomes for patients (Jones 2017; Smyth et al 2016; National Institute for Health and Care Excellence 2016). The idea for the project initiated from an adverse event that had happened in a NHS Trust where one of the students was working at the time. A patient had acquired sepsis in the community and it was thought staff had not intervened early enough. An investigation by the NHS Trust into the incident, found that not all community staff had been attending sepsis training or were not using the Trust's recommended guideline tools for the identification, decision making and escalation of concerns for people whose health was thought to be deteriorating because of sepsis. The Trust subsequently shared the findings with their staff and 
students. The IPE group thought that due to the life threatening nature of having sepsis and the high proportion of infections being acquired in the community, a project that helped community staff accesses learning material related to this would benefit the health and wellbeing of patients. An important aspect of ensuring the relevance of the service improvement project is the partnership working between clinical colleagues and the IPE group. In view of this the group initially sourced several stakeholders within the NHS Trust where the incident happened to see if there was any interest in finding a way to improve attendance at sepsis training events and increase uptake of using the NHS Trust's guideline tools. Three senior members of staff could see the potential benefit in the project and became the group's stakeholder: the Infection Control Lead, the Patient Safety Manager for Nursing and Quality Directorate and the Head of Clinical Effectiveness and Audit.

The students worked together to initially review the literature to find out the extent of community staff having difficulty in accessing education and training for sepsis recognition and found it to be a national problem (Health Education England 2016). Also, current training tends to focuses on hospital interventions and treatment as opposed to community based care (Culligan 2016).

Realising attendance at sepsis training for community staff was a problem, the IPE group wanted to find a way of potentially resolving this for their local area. The group returned to searching the literature and identified that e-Learning was seen to be beneficial to community staff in view of accessibility issues (Health Education England 2016), and videos can help improve acquisition of knowledge and skills (McKenny 2011; Cardoso, et al., 2012; Bloomingfield \& Jones, 2013).

Working with the stakeholder it was agreed that a short video would be the best option with the aim to raise awareness of the signs of sepsis. The video would also show the use of the NHS community screening tool to aid assessment and communication of an unwell patient. The video was primarily aimed at healthcare assistants, but could be used by any healthcare professional visiting patients in the community.

The students organised themselves to take on different tasks depending on the skill sets they could offer. Some were more focussed around sourcing the evidence to use in the video while others took on the role of scripting and acting out the scenario. The video aimed to role model skills with the impact of improving staff knowledge and skills in this area. The role modelling of good practice had been a key consideration of the video development as the IPE group wanted to ensure the skills that were demonstrated reflected professional standards and good practice. Role modelling and simulation of skills have also been shown to help improve clinical judgement (Coram 2016; Gaberson and Oermann 2010). 
The final video (Dixon et al 2017) used a mix of techniques such as still slides with written information or narration. A community based scenario acted and filmed by members of the group, showed a healthcare assistant and a first year student nurse visiting an elderly patient to provide catheter care and a wound dressing. On arrival at the home, they noticed that the patient was not looking very well. The scenario then showed the healthcare assistant assessing the patient's condition using the NHS Trust screening tool, recording the observations and then escalating her concerns.

The group showed the video as part of their assessment. Feedback from peers and lecturers was positive including comments such as, 'the video was creative and engaging'; 'the application of the observations the HCA and student took, really helped raise the importance of using the tool'.

A couple of areas needed developing, such as sound quality and some typographical errors in the text, which were changed. The video was also evaluated well by the stakeholders, who are now looking to incorporate the video into their sepsis training and place on the intranet. Further evaluation is needed to determine the clinical effectiveness of the video, but this was outside of the scope of the service improvement module and would have taken the project beyond the assessment guidelines and allocated timeframe.

The issue of ethics was an important consideration but as this was a service improvement project and did not involve research, ethics approval was not required. However, aspects such as integrity, honesty and safety were integral to the project development.

\section{Benefits and challenges of undertaking an interprofessional service improvement project}

Student feedback shows they like working within an interprofessional team and enjoy the autonomy in formulating the specifics of their project and the presentation style of the assessment. The ability to determine the scope and content of their product design facilitates the group to be self-directed and active in their learning, which resonates with the students' maturation in exposure to higher education learning and the proximity of their professional registration.

Being actively engaged in their learning students are developing skills of problem solving and critical thinking, both essential components of professional responsibility and quality nursing care (NMC 2018; Carvalho et al 2017). Yang and Jiang (2014) in their study exploring the relationship between self-directed learning and nursing competency among undergraduate nursing students found there was a strong positive correlation between both these elements. This suggests that being able to direct your own learning can enhance clinical competence. Enabling students to problem solve, think critically and apply their learning into practice are all attributes that current employers are seeking in 
their workforce to ensure they can practice effectively in a rapidly changing healthcare environment (Prime Minister's Commission 2010).

Students revealed in their individual, reflective accounts that they had learnt much more. They learnt that colleagues' priorities might not be their own and so developed strategies to work effectively with other people's agendas. They also understood the importance of interprofessional team working and respecting each other's views and values, particularly when they may be different from their own. Being respectful is a key component identified in the Framework for Action on Interprofessional Education and Collaborative Practice (WHO 2010) arguing that mutual respect can enable negotiation and joint working towards a common goal.

At times the students also realised that they had skills they didn't know they had. These included effectively leading a team of people, having confidence to challenge ideas and concepts appropriately as well as being able to work collaboratively with often, senior members of an organisation. The skills students are identifying clearly demonstrate personal qualities of selfawareness, self-confidence and self-knowledge and how they have used these help them adapt to work effectively with others. Having an understanding of the needs of the team and recognising other people's contributions and ideas are all features of leadership behaviour cited in the NHS Health Leadership Model (NHS Leadership Academy 2013). Understanding leadership behaviours and how they can affect the culture and climate of the environment that people work in can have a positive effect on the quality of care patients receive (NHS England 2016). Providing these opportunities for developing leadership capabilities within the undergraduate programme will better prepare students for the demands of complexities of clinical practice.

The module leader and facilitators acknowledge that the service improvement project is a challenging module for a variety of reasons, and these are also often cited by the students as suggestions for improvement. For example, the students live and work within a wide geographical area, so it is not always possible for them to meet face-to-face and some find this difficult if they are not used to using other methods of communication such as social media. Being able to work with new digital technology is an NHS Priority (Department of Health and Social Care 2018) and students will have to embrace this when newly qualified. This module provides a way to help encourage students to think about how technology can be used in order for example, to enhance communication and engagement with colleagues in the group.

Another challenge is that the academic and placement timetables are different between professional programmes and so require a lot of negotiation and compromise within the group in order to move the project forward. Also, students are working towards other assessments, which 
tend to be at different times so concentration often waivers from managing the project to working towards another assessment. However, it is felt that these challenges prepare students for the reality of work within a healthcare arena and feedback from employers recognise the benefits of the module and how it meets the needs of service.

"The opportunity to support and interprofessional group of students has been a real privilege and I have learnt so much from them in the process. Establishing the foundations of this at undergraduate level is going to ensure the next generation of healthcare workers are equipped to be part of the learning organisation we aspire to be" (Assistant Director of Nursing)

This module also provides an excellent way for the Faculty to engage with service partners for the benefit of patients and families. Currently the academic facilitators have not been asked their view of collaborating across programmes and engaging with interprofessional groups. It is recognised that is an area that needs further exploration.

\section{Conclusion}

The innovative approach to student learning offers practical application of essential attributes desired by employers on the completion of their programme such as critical thinking, team working and ethical practice. Collaborating with external partners in this way ensures benefits for both parties including the potential of a viable product that can improve the well-being of individuals and/or communities. The hands-on, practical delivery of the module prepares the student for the reality of work within a multiprofessional healthcare arena.

\section{References}

Bloomingfield J, Jones A (2013) Using e-learning to support clinical skills acquisition: exploring the experiences and perceptions of graduate first-year pre-registration nursing students- a mixed method study. Nurse Education Today 33(12): 1605-1611.

Cardoso A F, Moreli L, Braga F et al ( 2012) Effect of a video on developing skills in undergraduate nursing students for the management of totally implantable central venous access ports. Nurse Education Today 32(6): 709-713 doi.org/10.1016/j.nedt.2011.09.012

Carvalho D, Azevedo I, Cruz G et al (2017) Strategies used for the promotion of critical thinking in nursing undergraduate education: A systematic review. Nurse Education Today 57: 103-107. Centre for the Advancement of Interprofessional Education (2018) About Us: What is CAIPE? www.caipe.org (accessed 29 October 2018). 
Coram C (2016) Expert Role Modeling Effect on Novice Nursing Students' Clinical Judgement. Clinical Simulation in Nursing 12: 385-391.

Culligan F (2016) Improving management of sepsis in the community. Nursing Standard 31(1): p. 53.

Department of Health and Social Care (2018) The future of healthcare: our vision for digital, data and technology in health and care. https://www.gov.uk/government/publications/the-future-ofhealthcare-our-vision-for-digital-data-and-technology-in-health-and-care/the-future-of-healthcareour-vision-for-digital-data-and-technology-in-health-and-care

Dixon L-A, Tanci S, Dowland J et al (2017) Sepsis awareness and assessment within the community. [Online] Available at: https://www.youtube.com/watch?v=bmALR27ckec [Accessed 26 October 2018].

Francis R (2013) The Mid Staffordshire NHS Foundation Trust Public Inquiry http://webarchive.nationalarchives.gov.uk/20150407084231/http://www.midstaffspublicinquiry.co $\underline{m} /$ report

Gaberson K, Oermann M (2010) Clinical Teaching Strategies in Nursing 3rd edn. Springer Publishing Company New York.

Gage W, (2013) Using service improvement methodology to change practice. Nursing Standard 23: 51-57.

Gagon I, Roberge G D (2012) Dissecting the journey: nursing student experiences with collaboration during the group work process. Nurse Education Today

http://dx.doi.org/10.1016/j.nedt.2011.10.019

Health and Care Professions Council (2017) Standards for education and training http://www.hpcuk.org/assets/documents/10000BCF46345Educ-Train-SOPA5 v2.pdf

Health Education England (2016) Getting it right: The current state of sepsis education and training for healthcare staff across England, London: NHS Health Education England.

https://www.hee.nhs.uk/sites/default/files/documents/Getting\%20it\%20right\%20The\%20current\%2 Ostate\%20of\%20sepsis\%20education\%20and\%20training\%20for\%20healthcare\%20staff\%20across\% 20England.pdf (accessed 21 May 2019)

Jones J (2017) Managing Sepsis Effectively with National Early Warning Scores and Screening Tools. British Journal of Community Nursing 22(6): 278-281. 
Kirkup B (2015) The report of the Morcombe Bay Investigation

https://assets.publishing.service.gov.uk/government/uploads/system/uploads/attachment data/file $\angle 408480 / 47487 \mathrm{MBI}$ Accessible v0.1.pdf

McKenny K (2011) Using online video to teach nursing skills. Teaching and Learning in Nursing 6: $172-175$.

National Confidential Enquiry into Patient Otcome and Death (2015) Just Say Sepsis, London: NCEPOD.

National Institute for Health and Care Excellence (2016) Sepsis: Recognition, Diagnosis and early management [NG51], London: National Institute for Health and Care Excellence. (accessed 29 October 2018).

NHS England (2016) Leading Change, Adding Value: A framework for nursing, midwifery and care staff. https://www.england.nhs.uk/wp-content/uploads/2016/05/nursing-framework.pdf NHS Leadership Academy (2013) The Healthcare Leadership Model, version 1.0. Leeds: NHS Leadership Academy.

Nursing and Midwifery Council (2009) Standards for pre-registration midwifery education, London: Nursing and Midwifery Council.

Nursing and Midwifery Council (2018) Future nurse: Standards of proficiency for registered nurses. London: Nursing and Midwifery Council.

Prime Minister's Commission (2010) Front Line Care: the future of nursing and midwifery in England. Report of the Prime Minister's Commission on the Futire of Nursing and Midwifery in England. https://webarchive.nationalarchives.gov.uk/20100331110440/http://cnm.independent.gov.uk/thereport/

Smyth M, Brace-McDonnell S, Perkins G (2016) Identification of adults with sepsis in the prehospital environment: a systematic review. British Medical Journal., Online dx.doi.org/10.1136/bmjopen$\underline{2016-011218}$

UK Sepsis Trust (2017) The Sepsis Manual $4^{\text {th }}$ edition 2017-2018 https://www.e-lfh.org.uk/wpcontent/uploads/2018/02/Sepsis Manual 2017 final v7.pdf

World Health Organisation (2010) Framework for Action on Interprofessional Education \& Collaborative Practice http://www.who.int/hrh/nursing midwifery/en/ 
Yang G-U, Jiang X-Y (2014) Self-directed learning readiness and nursing competency among undergraduate nursing students in Fujian province China. International Journal of Nursing Sciences 1(3): 255-259. 